\title{
A new index for assessing heavy metal contamination in sediments of the Beijing-Hangzhou Grand Canal (Zaozhuang Segment): A case study
}

\author{
Wen Zhuang ${ }^{\mathrm{a}, \mathrm{c}, *}$, Yongxia Liu ${ }^{\mathrm{a}}$, Qing Chen ${ }^{\mathrm{b}}$, Qian Wang ${ }^{\mathrm{a}}$, Fengxia Zhou ${ }^{\mathrm{c}}$ \\ a College of City and Architecture Engineering, Zaozhuang University, Zaozhuang, Shandong 277160, China \\ b College of Life Sciences, Zaozhuang University, Zaozhuang, Shandong 277160, China \\ ${ }^{\mathrm{c}}$ Key Laboratory of Coastal Environmental Processes and Ecological Remediation, Yantai Institute of Coastal Zone Research, Chinese Academy of Sciences, \\ Yantai, Shandong 264003, China
}

\section{A R T I C L E I N F O}

\section{Article history:}

Received 27 December 2015

Received in revised form 30 March 2016

Accepted 14 April 2016

Available online 10 May 2016

\section{Keywords:}

Heavy metal

Sediment

New index

Contamination

The Beijing-Hangzhou Grand Canal

\begin{abstract}
A B S T R A C T
Zaozhuang Segment of the Beijing-Hangzhou Grand Canal is an important water conveyance line on the eastern route of the South-North Water Transfer Project in China and its water environment condition can exert a significant influence on diversion water quality safety. This paper analyzed contents of five heavy metals such as $\mathrm{Cd}, \mathrm{Cu}, \mathrm{Ni}, \mathrm{Pb}$ and $\mathrm{Zn}$ as well as their chemical forms in surface sediments in this region. Methods including Threshold Effects Level-Probable Effects Level (TEL-PEL), Risk Assessment Code (RAC) and Acid Volatile Sulfide- Simultaneously Extracted Metals (AVS-SEM) were also employed to evaluate the quality of sedimentary environment in this region. With the aim to assess the eco-environmental risk revealing the information of the concentration, the chemical fractionation, the toxicity of heavy metals, a new assessment index known as Multivariable Evaluation Index (MEI) was introduced into this paper. Results indicated that contents of such five heavy metals in surface sediments were generally low. Overall, ecological risk was in the medium-low grade in addition to several locations where the level of risk was high. However, certain differences still existed among various assessment results. Comparing with other single evaluation methods, MEI may be able to reflect contamination status and ecological risks of heavy metals in sediments of a specific region more comprehensively. MEI also seemed able to overcome the limitations of other prevalent aggregated indexes to assess potential sediment pollution risk in aquatic systems.
\end{abstract}

(c) 2016 Elsevier Ltd. All rights reserved.

\section{Introduction}

Heavy metal usually refers to the more than 40 kinds of metals with a specific gravity greater than 5 , such as copper, lead, zinc, ferrum, cobalt, nickel, manganese, cadmium, chromium, mercury, wolframium, molybdenum, gold and silver, etc. It is very difficult to degrade heavy metals which are toxic and can be accumulated within organisms in natural environment. Consequently, negative impacts on ecological environment and human health are featured with the elusive, the hysteresis and the persistence. Heavy metal contamination has been a hot issue worldwide for many years. Due to industrial and agricultural pollution discharge, sanitary sewage as well as combustion and shipping of fossil fuel, etc., contentS of heavy metals in water

\footnotetext{
* Corresponding author.

E-mail address: wzhuang@yic.ac.cn (W. Zhuang).
}

environment show up a trend of growing continuously (Gao et al., 2014; Saeedi and Jamshidi-Zanjani, 2015; Zhuang and Gao, 2015).

As an important heavy metal bank in aquatic environment which including oceans, lakes and rivers, etc., the sediment is not only sink of heavy metals in overlying water, but also essential sources of them in water body (Bastami et al., 2012). While contents of heavy metals in water body vary rapidly and have strong mobility, their contents in the sediment are relatively stable. Therefore, sediments can record variation history of heavy metals in a specific region within a long temporal scale.

At present, there are many methods that can be utilized to evaluate heavy metal contaminations or ecological risks in sedimentary environment internationally, and principles of those methods are different from each other. Some depend on the total amount of heavy metals in sediments, some on their chemical forms and some on a content relation between heavy metals and acid volatile sulfide (AVS) in sediments and so on. 
Threshold effects level (TEL) and probable effects level (PEL) defined in Sediment Quality Guidelines (SQGs) for heavy metal in aquatic sediments are extensively applied assessment methods for total heavy metal amount in sediments (Long et al., 2000; Sundaray et al., 2011). They have been used to determine concentration thresholds of the heavy metals which are able to give rise to biotoxicity and other negative biological effects in sediments. In case that the concentration of a heavy metal in sediment is lower than corresponding TEL value, it is almost impossible for negative biological effects to take place. In comparison, if higher than PEL value, negative biological effects are able to occur frequently. Moreover, if the concentration falls in between, negative biological effects may happen occasionally.

Bio-availability of the heavy metals in sediments is related to corresponding gross and under the control of environmental factors such as the content of iron and manganese oxides in sediments, type of clay mineral, content of organic carbon as well as the content of AVS, etc. Such geochemistry properties usually exert influences on toxicity and bio-availability of heavy metals by changing their fractionation and chemical forms. Thus, chemical forms play decisive roles in the bio-availability of heavy metals. Researches on fractionation characteristics of heavy metals are able to better reflect their true impacts on environment (Fytianos and Lourantou, 2004; Gao et al., 2010; Zhang et al., 2013; Zhuang and Gao, 2014). Although heavy metals in sediments have different sources such as the native and the natural sources, their bound forms in sediments are featured with university. According to Gibbs (1977), heavy metals in aquatic sediments have four combination types of an absorbed state, a fractionation co-precipitating with hydrated iron and manganese oxides, an organic molecule speciation and a fractionation combined in mineral crystal lattice. This categorization has been widely recognized around the world. Risk Assessment Code (RAC) is a common risk evaluation method based on the chemical forms of heavy metal (Perin et al., 1985).

AVS is the general term for several sulfides defined in line with operational processes. According to interpretations given by United States Environment Protection Agency (USEPA, 2004), AVS refers to sulfides which can volatilize and give off $\mathrm{H}_{2} \mathrm{~S}$ by cold acid treatment; and it is expressed by the content of $\mathrm{S}^{2-}$ in actual measurement. In the process of AVS extraction, the heavy metal extracted from sediments is named as Simultaneously Extracted Metals (SEM) which mainly consists of $\mathrm{Cd}, \mathrm{Cu}, \mathrm{Ni}, \mathrm{Pb}$ and $\mathrm{Zn}$ (USEPA, 2004). In addition, AVS generally exists in recent sediments in the form of solid FeS which is the metastable state during its transformation into pyrite and is also unstable from perspective of thermodynamics and kinetics. Thanks to a strong interaction between AVS and divalent heavy metal ions (usually including $\mathrm{Cd}, \mathrm{Cu}, \mathrm{Ni}, \mathrm{Pb}$ and $\mathrm{Zn}$ ) in sediments, those ions can replace $\mathrm{Fe}^{2+}$ in iron sulfide compounds by means of $\mathrm{Me}^{2+}+\mathrm{FeS} \rightarrow \mathrm{MeS}+\mathrm{Fe}^{2+}$ ( $\mathrm{Me}^{2+}$ representing the divalent metal ions) to generate sulfides with lower solubility than that of FeS so as to be removed out of sediment pore water through precipitation and reduce both the movability and the biochemical activity of the heavy metal in sediments (Morse et al., 1987; Carlson, 1991). Meanwhile, large amounts of hydrogen sulfides $\left(\Sigma \mathrm{H}_{2} \mathrm{~S}=\mathrm{H}_{2} \mathrm{~S}(\mathrm{aq})+\mathrm{HS}^{-}+\mathrm{S}^{2-}\right)$ dissolved in pore water also have a toxic and side effect on many benthos. In order to reduce the toxic and side effect on related benthic community, metal sulfides are formed to immobilize free hydrogen sulfides and this is a critical mechanism (Bagarinao, 1992). For above substitution reaction, it takes place in accordance with a mole ratio of $1: 1$ between the concentration of metal ions and $S^{2-}$ (hereinafter expressed by [AVS] and [SEM], unit: $\mu \mathrm{mol} \mathrm{g}^{-1}$ ). Therefore, the mole concentration proportion of [SEM]/[AVS] can be adopted to decide and predict the chemical activity of toxic metals in sediments (USEPA, 2004).
Research purposes of this paper are as follows. Firstly, contents and occurrence forms of heavy metals including $\mathrm{Cd}, \mathrm{Cu}, \mathrm{Ni}, \mathrm{Pb}$ and $\mathrm{Zn}$ in surface sediments in Zaozhuang Segment of the BeijingHangzhou Grand Canal (hereinafter referred to as "Zaozhuang Segment") are analyzed. Secondly, multiple methods are adopted to evaluate contamination degree and potential ecological risk of heavy metals in surface sediments. Thirdly, an attempt is made to establish a new comprehensive assessment method covering the gross and the fractionation of metal as well as its relation with AVS content.

\section{Materials and methods}

\subsection{Study area}

As a water transfer project benefitting the largest population in the world, the South-North Water Transfer Project is a strategic infrastructure for cross-regional water resource distribution in China and one of the water transportation projects with the largest scale. The eastern line of this project has an entire length of $1191 \mathrm{~km}$ which has supplied water in 2013 officially to make extremely important contributions to the serious situation of water resource shortage in Northern China. Among which, the Zaozhuang Segment is a key part of this project. Starting at the east mouth of the Nansihu Lake, the largest impoundment lake on the Eastern Line of the South-North Water Transfer Project, Zaozhuang Segment feeds into the Middle Canal in Jiangsu with a total length of $42.5 \mathrm{~km}$.

Zaozhuang Segment lies in the zone between western edge of Shandong hills and the Yellow River alluvial plain, low-lying east to the west. It has a semi-humid monsoon climate in the warm temperate zone, with four distinct seasons and adequate light. It is arid and windy in spring, hot and rainy in summer, cool and nice in autumn, and cold and dry in winter. The annual average temperature is $14.2^{\circ} \mathrm{C}$, and the annual range and daily range of temperature are small, with the average temperature of $-0.3^{\circ} \mathrm{C}$ in January and $26.5^{\circ} \mathrm{C}$ in July. Annual average sunshine hours are totally 2516 , and the average annual rainfall is $700 \mathrm{~mm}$ (Shen et al., 2008).

Currently, 4 integrated ports as well as a "Golden Waterway" and a "National Model Channel of Civilization" where 1000-ton ships can go through throughout the year are located in Zaozhuang Segment. Moreover, along the segment, industrial enterprises of different sizes are distributed, such as thermal power plants, metallurgic plants, paper mills, machinery works and cement plants, etc. While China National Highway 104, the Beijing-Taipei Highway and the Beijing-Shanghai Railway pass through on Zaozhuang Segment's west. Zaozhuang Segment is close to Xuzhou City on the south. Pillar industries in Xuzhou are steel, coal and electricity, etc. Undoubtedly, these industries are great threats to the ecological environment of this drainage basin and along the entire Eastern Line of the South-North Water Transfer Project. Besides, they may be primary sources of the heavy metal in environment. Therefore, pollution problems of heavy metals in regional environment here cannot be neglected.

\subsection{Sample collection}

Stainless steel bottom sampler was utilized to collect 14 surface sediment samples $(0-5 \mathrm{~cm}$, shown in Fig. 1) at the Zaozhuang Segment in April, 2015. The sampling area ranged from the eastern mouth of the Nansihu Lake to the Tai'erzhuang District of Zaozhuang. Samples after homogeneous mixing were put into polyethylene bags and rapidly loaded into a warm-box with ice packs. Before sampling, the polyethylene bag had been soaked for more than $48 \mathrm{~h}$ in $10 \% \mathrm{HNO}_{3}(\mathrm{v} / \mathrm{v})$ and washed out with Milli-Q water. 


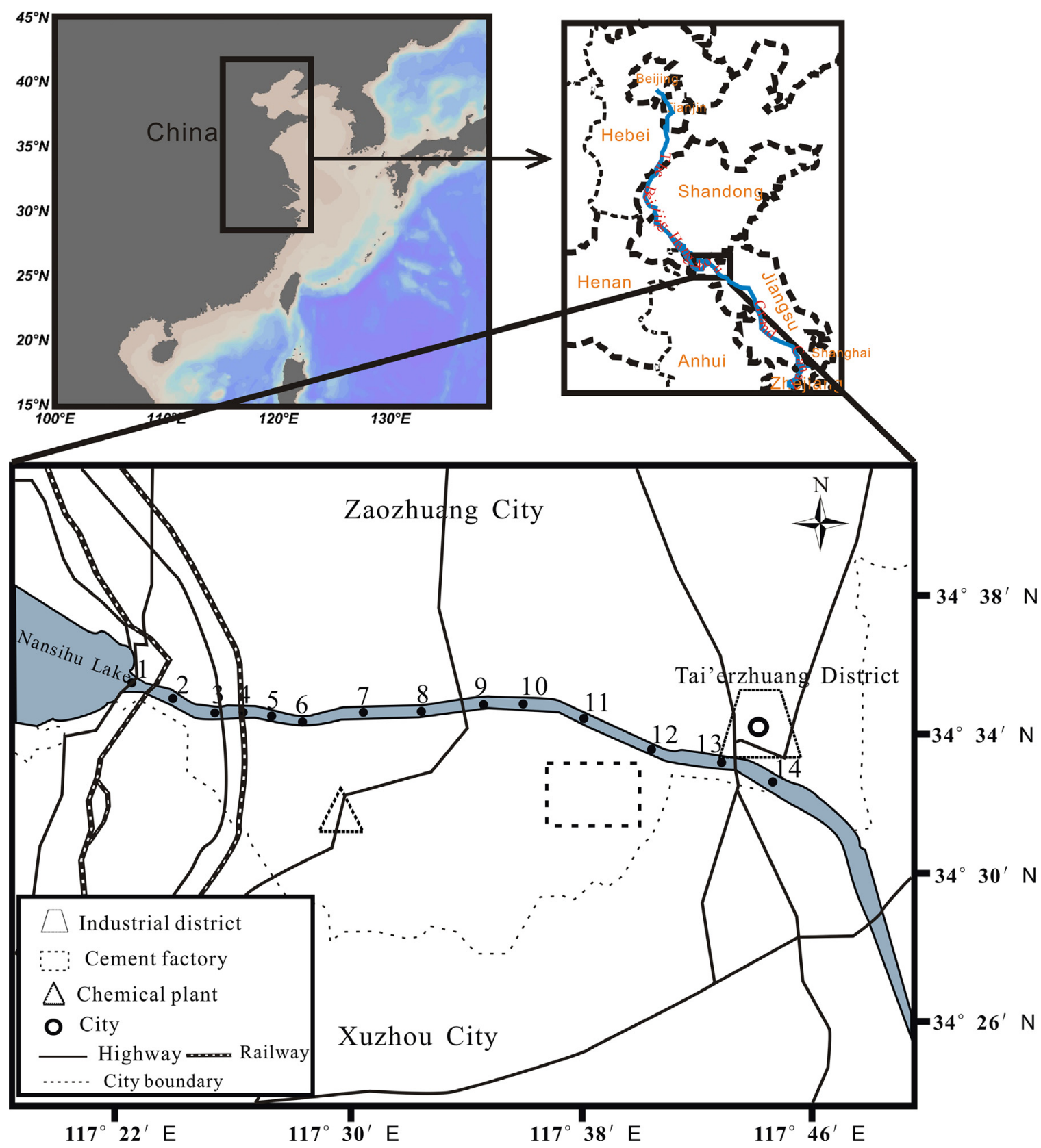

Fig. 1. Location of the sampling sites in the Beijing-Hangzhou Grand Canal (Zaozhuang Segment).

After shipping into the laboratory, samples were stored at $4^{\circ} \mathrm{C}$. During the sampling, water flowed from east to west.

\subsection{Chemical analysis}

\subsubsection{Heavy metal content analysis}

After natural withering in a cool and ventilated place, samples were grounded and passed through \#200 mesh sieve. Then, $0.1000 \pm 0.0001 \mathrm{~g}$ of samples were accurately taken and placed into polytetrafluoroethylene degradation tanks in which $2 \mathrm{~mL} \mathrm{HNO}_{3}$ and $0.2 \mathrm{~mL} \mathrm{H}_{2} \mathrm{O}_{2}$ were added. After ultrasonic treatment for $1 \mathrm{~h}$, thermal insulating was carried out for them for $24 \mathrm{~h}$ at $60^{\circ} \mathrm{C}$ on the electric heating plate to dry the samples. Then, $\mathrm{HNO}_{3}$ of $2 \mathrm{~mL}$ was also added, and kept warm overnight after ultrasonic treatment for $1 \mathrm{~h}$. After that, $2 \mathrm{~mL} \mathrm{HF}$ was added at $60^{\circ} \mathrm{C}$ for heat preservation of $24 \mathrm{~h}$ with an aim to dry the samples as well. After the addition of $5 \mathrm{~mL} \mathrm{HNO}_{3}$ and $2 \mathrm{~mL} \mathrm{HF}$, samples were put into reaction kettles for degradation lasting $48 \mathrm{~h}$ at $190^{\circ} \mathrm{C}$. With an addition of $1 \mathrm{~mL}$ $\mathrm{HClO}_{4}$, the polytetrafluoroethylene tanks after degradation were placed on the electric heating plate at a temperature less than $100{ }^{\circ} \mathrm{C}$ to get rid of acid until corresponding fluid exhibited a state of sticky droplets. Solutions after acid removal were transferred to polyethylene bottles where $2 \% \mathrm{HNO}_{3}(\mathrm{w} / \mathrm{w})$ were added into with a constant volume of $50 \mathrm{~g}$. Such a degradation procedure was able to guarantee that sediment samples were completely degraded so as to obtain clear solutions. Furthermore, contents of $\mathrm{Cd}, \mathrm{Cu}, \mathrm{Ni}, \mathrm{Pb}$ and $\mathrm{Zn}$ were measured by ICP-MS (PerkinElmer Elan DRC II).

\subsubsection{Chemical form analysis of heavy metals}

Morphosis extracting of the heavy metals in surface sediment can be performed by BCR continuous extraction method (Rauret et al., 1999) according to which the geochemical fractionations of heavy metals are divided into four kinds: a speciation of exchangeable specie and carbonate, a speciation of ferromanganese oxide or 


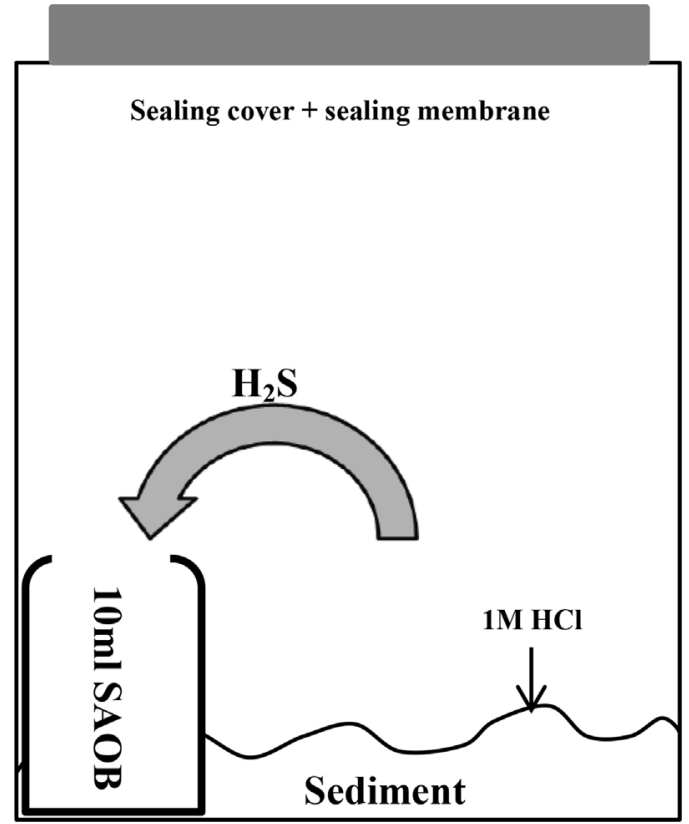

Fig. 2. Schematic diagram of cold diffusion method.

its hydrated oxide, an organic speciation and a residual form. In this paper below, those four chemical forms were briefly named as F1, F2, F3 and F4. Contents of $\mathrm{Cd}, \mathrm{Cu}, \mathrm{Ni}, \mathrm{Pb}$ and $\mathrm{Zn}$ fractionations were measured by ICP-MS. In addition, with regard to four fractionations of each metal, the numerical difference between the sum of their contents and the gross measurement results should be no more than $10 \%$.

\subsubsection{Measurement of AVS and SEM}

Commonly used methods for AVS and SEM extractions consist of the Purge and Trap Method (Morse et al., 1987) and the Cold Diffusion Method (van Griethuysen et al., 2002). Comparing with the latter, the former takes much time and lots of energies to deal with large amount samples as a great deal glassware as well as plentiful gases and spaces are required. Relevant researches have indicated that in comparison with the Purge and Trap Method, the Cold Diffusion Method can be employed to extract more AVS as it is more efficient and samples can stay in an anaerobic environment for a longer time (Brouwer and Murphy, 1994; Leonard et al., 1996; van Griethuysen et al., 2002). Considering several points mentioned above, a Cold Diffusion Method which was slightly modified based on experimental facilities of van Griethuysen et al. (2002) was selected to extract AVS and SEM in this experiment. The corresponding set-up diagram was shown in Fig. 2.

Concrete operational procedures were described as follows. Under an environment of nitrogen protection, a wet sediment sample of $3 \mathrm{~g}$ and a small polyethylene bottle containing $10 \mathrm{~mL}$ sulphide anti-oxidation buffer (SAOB) were put into a $250 \mathrm{~mL}$ widemouth polyethylene bottle. Sediments were spread on bottom of the wide-mouth bottle as flat as possible. Then, $10 \mathrm{~mL}$ deoxidized $\mathrm{HCl}\left(1 \mathrm{~mol} \mathrm{~L}^{-1}\right)$ was added into the wide-mouth bottle the plug of which was rapidly capped tightly for reaction of $18 \mathrm{~h}$. After the completion of reaction, the small bottle of SAOB solution was taken out. The mixture of sediment and $\mathrm{HCl}$ was shifted into a $50 \mathrm{~mL}$ centrifuge tube together with the $2 \% \mathrm{HNO}_{3}(\mathrm{w} / \mathrm{w})$ solution which had been used to wash the $250 \mathrm{~mL}$ polyethylene bottle adopted for reactions for several times. After $10 \mathrm{~min}$ of centrifugation at a speed of $4000 \mathrm{rpm}$, supernatant was shifted into a polyethylene bottle filled with $2 \% \mathrm{HNO}_{3}(\mathrm{w} / \mathrm{w})$ to $30 \mathrm{~g}$. Components of SAOB were $2 \mathrm{~mol} \mathrm{~L}^{-1} \mathrm{NaOH}, 0.2 \mathrm{~mol} \mathrm{~L}^{-1}$ ascorbic acid and $0.2 \mathrm{~mol} \mathrm{~L}^{-1}$ EDTADisodium (van Griethuysen et al., 2002).
A series with sodium sulphide whose concentration had been known were prepared as the standard solution to measure AVS. In addition, Silver sulfide ion-selective electrode was employed to measure potential value (Eh). The standard curve between Eh and logarithm of concentration was drawn (Allen et al., 1993; van Griethuysen et al., 2002; Hinkey and Zaidi, 2007; De Jonge et al., 2012). When correlation coefficient $R^{2}$ of a curve was more than 0.999 , the curve was deemed to be available. Moreover, contents of $\mathrm{SEM}(\mathrm{Cd}, \mathrm{Cu}, \mathrm{Ni}, \mathrm{Pb}, \mathrm{Zn})$ were measured by ICP-MS.

\subsubsection{Quality assurance and quality control ( $Q A / Q C)$}

Based on quality assurance in the laboratory and the adoption of quality control methods, reliability of data can be guaranteed. They consist of formal experimental procedures, analytical reagent blank, calibration by addition, reference material recovery and analysis of parallel samples. All reagents were guarantee ones or the guaranteed reagents through secondary purification processing, and all glassware and plastic containers had been soaked in $10 \%$ $(\mathrm{v} / \mathrm{v})$ for over $48 \mathrm{~h}$ before using. Afterwards, they were washed out by Milli-Q and then dried. Recovery of metallic elements in sediment samples were estimated based on the recovery of reference materials. Serial numbers of the reference material used to analyze components of stream sediments were GBW-07333 and GBW-07309. Furthermore, the difference between the measured value and appraisal value of the reference material was within $10 \%$. For the measurement method of AVS recovery, $\mathrm{Na}_{2} \mathrm{~S} \cdot 9 \mathrm{H}_{2} \mathrm{O}$ with known contents was mixed into the sediment sample which was conducted simultaneously with the AVS extracting experiments of other samples. At last, the content of recovered $\mathrm{Na}_{2} \mathrm{~S} \cdot 9 \mathrm{H}_{2} \mathrm{O}$ was measured. Related results showed that the recovery ranges from $92 \%$ to $109 \%$. The instrument testing precision was estimated by Relative Standard Deviation (RSD). Concerning two measurement values for each element of the same sample, their RSD was within $5 \%$; measurements for all samples were performed twice for each and corresponding results were expressed by an average value.

\subsection{Estimation of sediment contamination}

\subsubsection{Sediment quality guidelines (SQGs) and mean PEL quotient}

In case that the concentration of heavy metal in sediments is lower than TEL, the adverse bio-toxicity effect rarely takes place. In comparison, when such a concentration becomes higher than TEL, this effect should occur frequently. If the concentration is between TEL and PEL, the effect happen occasionally (MacDonald et al., 1996). The heavy metal concentration corresponding to TEL and PEL specified in Freshwater Sediment Standard of Canada can be seen in Table 1.

Considering that the joint toxical effect often happens to heavy metals in sediments, the mean PEL quotient is adopted to decide the occurrence probability of those heavy metals, and its formula is shown below.

\section{MeanPELquotient $=\Sigma\left(\mathrm{C}_{\mathrm{x}} / \mathrm{PEL}_{\mathrm{x}}\right) / \mathrm{n}$}

In this equation, $C_{x}$ refers to the concentration of element $x$ in sediments, while $\mathrm{PEL}_{\mathrm{x}}$ refers to the PEL value corresponding to element $\mathrm{x}$ and $\mathrm{n}$ refers to the species number of elements. When the mean PEL quotient value is smaller than 0.1, the occurrence

Table 1

The metal guideline values of TEL and PEL and background values of the studied area (unit: $\mu \mathrm{gg}^{-1}$ dry weight).

\begin{tabular}{lllllll}
\hline & $\mathrm{Cd}$ & $\mathrm{Cu}$ & $\mathrm{Ni}$ & $\mathrm{Pb}$ & $\mathrm{Zn}$ & References \\
\hline TEL guideline & 0.6 & 36 & 18 & 35 & 123 & Moore et al. (1992) \\
PEL guideline & 3.5 & 197 & 36 & 91 & 315 & \\
Back ground value & 0.077 & 13 & 20 & 15 & 40 & Zhao and Yan (1992) \\
\hline
\end{tabular}


probability of bio-toxicity is $8 \%$; however, if the value lies between 0.11 and 1.5 , such a probability becomes $21 \%$; and if the value lies between 1.51 and 2.3, it reaches $49 \%$; finally, if the value is larger than 2.3 , such a probability is $73 \%$ (Long et al., 2000).

\subsubsection{Risk assessment code (RAC)}

Risk Assessment Code is a common ecological risk assessment index and its formula can be shown as follows (Perin et al., 1985):

$\mathrm{RAC}=\mathrm{Exc} \%+\mathrm{Carb} \%$

Exc\% and Carb\% represent percentages taken by the exchangeable form and the carbonate bound form (that is F1 mentioned in this paper) in the gross of corresponding metal. Sediments can be divided into five grades in line with the risk assessment index. Firstly, RAC $\leq 1 \%$ refers to no risks; secondly, $1 \%<\mathrm{RAC} \leq 10 \%$ refers to low risks; thirdly, $10 \%<\mathrm{RAC} \leq 30 \%$ refers to risks at a medium level; fourthly, $30 \%<\mathrm{RAC} \leq 50 \%$ refers to high risks; fifthly, $50 \%<$ RAC refers to sky-high risks. Such a method has been established based on the chemical forms of heavy metals. Comparing with gross, chemical form has more capabilities to reflect the percentage of heavy metals with biological effectiveness in the gross. However, this method leaves both the gross and the toxicity intensity of heavy metals out of account, and if used independently, misleading conclusions might be made.

\subsubsection{AVS and SEM}

AVS plays an important role in controlling the partition of sediment/pore water, reducing toxic effects of heavy metal and free hydrogen sulfide on benthos as well as formulating the sediment heavy metal contamination quality baseline, etc. (Bagarinao, 1992). In an anaerobic sedimentary environment, the relation of molar concentration between AVS and SEM is often adopted to decide whether the sediments have the eco-toxicity of heavy metal (USEPA, 2004). If [SEM] $/[$ AVS $]>1$ or $[\mathrm{SEM}]-[\mathrm{AVS}]>0$, as AVS is unable to be combined with SEM, excessive SEM may be free from sediments to produce toxic effects and lead to the death of benthos; if $[\mathrm{SEM}] /[\mathrm{AVS}]<1$ or $[\mathrm{SEM}]-[\mathrm{AVS}]<0$, it is deemed that enough sulfides exist in the sedimentary environment for the purpose of being in combination with divalent metals so that the existence possibility of toxic effects of the heavy metal is relatively small (Allen et al., 1993; Di Toro et al., 1990, 2005; McGrath et al., 2002; Hinkey and Zaidi, 2007; De Jonge et al., 2009, 2010; Zhuang and Gao, 2013).

On the basis of this theory, sediments can be otherwise categorized into three grades. Grade 1, the heavy metal in sediments is likely to have toxic effects on organisms ([SEM] - [AVS] > 5; unit: $\left.\mu \mathrm{molg}^{-1}\right)$; Grade 2 , the heavy metal in sediments occasionally has toxic effects on organisms $(0<[\mathrm{SEM}]-[\mathrm{AVS}]<5)$; Grade 3 , the heavy metal in sediments occasionally has no toxic effects on organisms ([SEM] - [AVS] < 0) (USEPA, 2004).

\subsubsection{Multivariable evaluation index (MEI)}

In order to take the relation between AVS content and heavy metal as well as the gross and fractionation of the latter into a comprehensive consideration, Multivariable evaluation Index (MEI) was introduced into this paper. Besides, in view of different bio-toxicity intensity in each heavy metal, toxic response factor (Hakanson, 1980) had been brought into as another assessment index. The formula of MEI is,

$\mathrm{MEI}=\left(\Sigma[\mathrm{SEM}]-[\mathrm{AVS}]+\Sigma\left(\mathrm{RAC}_{\mathrm{i}} \times \operatorname{Tr}_{\mathrm{i}}\right)\right) / \mathrm{n}$

$\Sigma[$ SEM $]-[A V S]$ is the difference between SEM and AVS, RAC $C_{i}$ is the percentage composition of exchangeable form and carbonate bounded form for heavy metal $\mathrm{i}, \mathrm{Tr}_{\mathrm{i}}$ is the toxic response factor of heavy metal $\mathrm{i}$. The toxic response factor for $\mathrm{Cd}, \mathrm{Cu}, \mathrm{Ni}, \mathrm{Pb}$ and $\mathrm{Zn}$ respectively are 30, 5, 5, 5 and 1 (Hakanson, 1980). $n$ represents
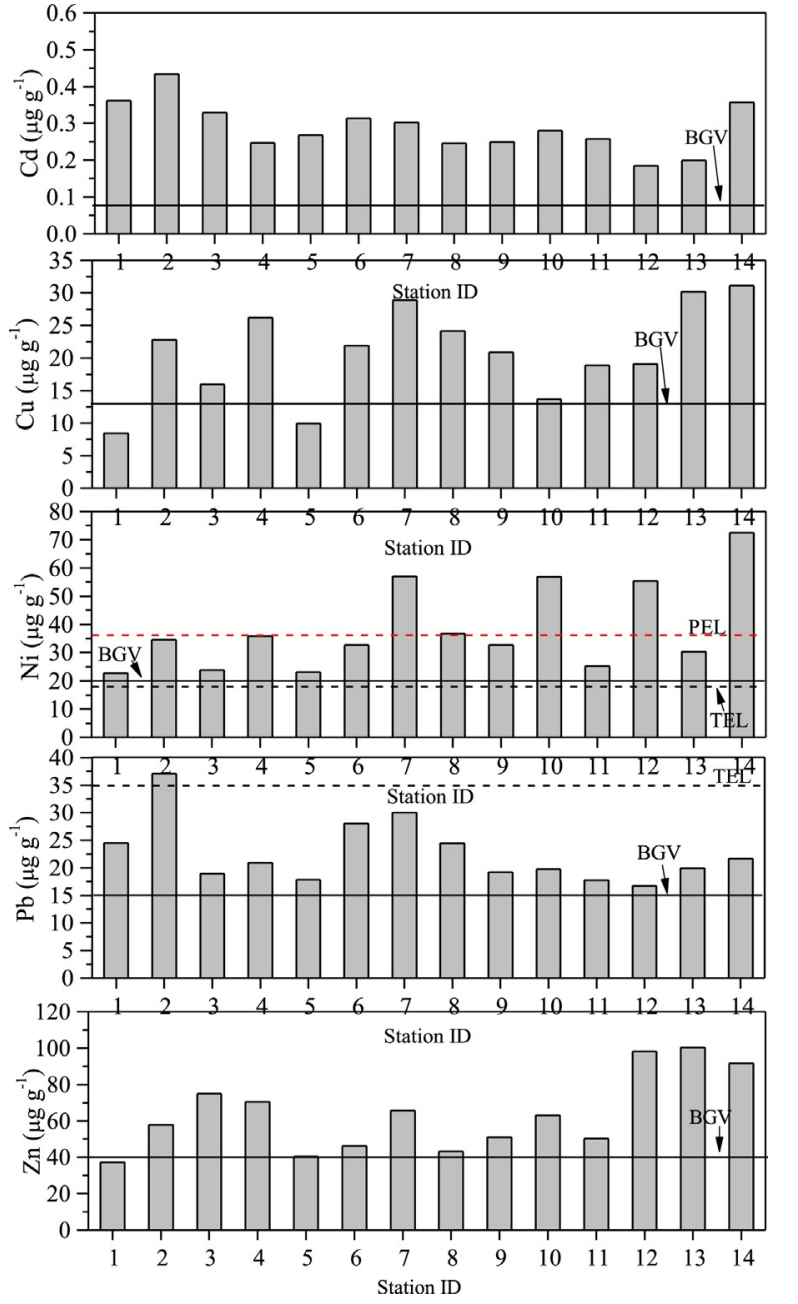

Fig. 3. The spatial variations of studied metals in total concentrations of the surface sediments from the Zaozhuang Segment. The horizontal dash lines represent their corresponding TEL or PEL concentrations; the horizontal solid lines represent their corresponding background values (BGV).

the number of species of heavy metals. Due to the lack of relevant toxicology experiment data, the risk gradation range of this index remains undecided temporarily. As a result, value comparison was only performed for the calculation result obtained by such an assessment index and other assessment indexes. This method only serves as a reference for related scholars.

\section{Results and discussions}

\subsection{Total metal content}

Gross distribution of heavy metals is shown in Fig. 3. Zaozhuang Segment belongs to Nansi Lake drainage area which is a basin formed and silted up by inundated sediments from the Yellow River. Therefore, background value of Yellow River sediments was used as the environmental background value of this research area (see Table 1). Contents of $\mathrm{Cd}, \mathrm{Ni}$ and $\mathrm{Pb}$ in surface sediments located at corresponding positions were all higher than their background values. In Position 1 and 5, the contents of $\mathrm{Cu}$ in the surface sediments were no more than the corresponding background value. But contents of $\mathrm{Cu}$ in other positions were higher than the background value. The content of $\mathrm{Zn}$ in surface sediments of all positions exceeded the background value except in Position 1. By comparing with the background value, it is indicated that the research area might be bearing huge pressures created by industrialization and 
urbanization under rapid development. Nevertheless, background values for different regions can significantly vary numerically. The content of heavy metal which is higher than its background value does not mean that certain contaminations or ecological risks exist for sure. As a consequence, it requires further researches.

\subsection{Metal fractionation}

Fractionation of heavy metal provides information of its chemical form and intensity in sediments, which is beneficial for the evaluation of its influence on organisms in aquatic ecosystems (Sundaray et al., 2011; Zhuang and Gao, 2014). F1 fractions of heavy metals (including exchangeable state and carbonate bounded form) are mainly brought into the natural environment through human activities. F1 fractions have relatively high bio-availability and are serious environmental hazards. F2 fractions (Fe/Mn oxides or a bond form of its hydrated oxides) could be emitted by reduction so as to acquire bio-availability again. In comparison, organic matters decompose into inorganic substances by mineralization in an environment of oxidization, so that F3 fractions (organic bond form) can be released into the water body again. For F4 fractions (residual form) that is the inert constituent of heavy metal in sediments, it is mineral phase principally and bonded in crystal gratings of sediments; moreover, as a natural source constituent of heavy metal, it is nearly unavailable to organisms.

Various fractionation contents of the heavy metals in surface sediments in Zaozhuang Segment are shown in Fig. 4. On the whole, $\mathrm{Cd}, \mathrm{Cu}, \mathrm{Ni}$ and $\mathrm{Zn}$ existed as $\mathrm{F} 4$ and originated from minerals. Besides F4, percentage composition and bioactivity of Cd in F1 were also relatively high exhibiting prominent sources of human activity. $\mathrm{Pb}$ existed in enormously great proportions as F2 and F3 showing potential biological risks. Fractionations of every heavy metal showed obvious differences in their positions due to possible variations of physical chemistry conditions for corresponding sediments and human pollution discharges, etc. Content sequence of four chemical fractionations in $\mathrm{Cd}, \mathrm{Cu}, \mathrm{Ni}, \mathrm{Pb}$ and $\mathrm{Zn}$ are described below: $\mathrm{F} 4>\mathrm{F} 1>\mathrm{F} 2>\mathrm{F} 3 ; \mathrm{F} 4>\mathrm{F} 1 \approx \mathrm{F} 2 \approx \mathrm{F} 3 ; \mathrm{F} 4>\mathrm{F} 3>\mathrm{F} 1 \approx \mathrm{F} 2 ; \mathrm{F} 2>\mathrm{F} 4>\mathrm{F} 3>\mathrm{F} 1$; $\mathrm{F} 4>\mathrm{F} 1>\mathrm{F} 2>\mathrm{F} 3$.

\subsection{Assessment of sediment contamination}

\subsubsection{TEL-PEL guideline}

The values of TEL and PEL effect were listed in Table 1 and lined out in corresponding positions in Fig. 3. Contents of $\mathrm{Cd}, \mathrm{Cu}$ and $\mathrm{Zn}$ in surface sediments in their locations were not in excess of their own TEL values. Hence, the possibility for them to produce adverse biological effects was very low. In Location 2 , the content of $\mathrm{Pb}$ was slightly higher than its TEL value and far smaller than its PEL value, so unbeneficial impacts might be generated occasionally on organisms. In other locations, as the Pb content was all less than TEL, it was almost impossible to generate adverse biological actions. Clearly, although contents of $\mathrm{Cd}, \mathrm{Cu}, \mathrm{Pb}$ and $\mathrm{Zn}$ in most locations all exceeded local environmental background value, it was uncertain about whether obvious environmental hazards could occur. As the contents of $\mathrm{Ni}$ in all locations were higher than the TEL value and even higher than the PEL value in Location 7, 8, 10, 12 and 14, adverse bio-toxicity effects might frequently take place. Concerning the related reason, it might be the pollution discharged from local metal smelting enterprises of large and small sizes.

Mean PEL Quotient is employed to decide the occurrence probability of joint toxicity effect for multiple heavy metals. According to the calculation result analysis of it, it was known that the comprehensive toxicity occurrence probability of 5 heavy metals in all locations is $21 \%$ in this study (Fig. 5).
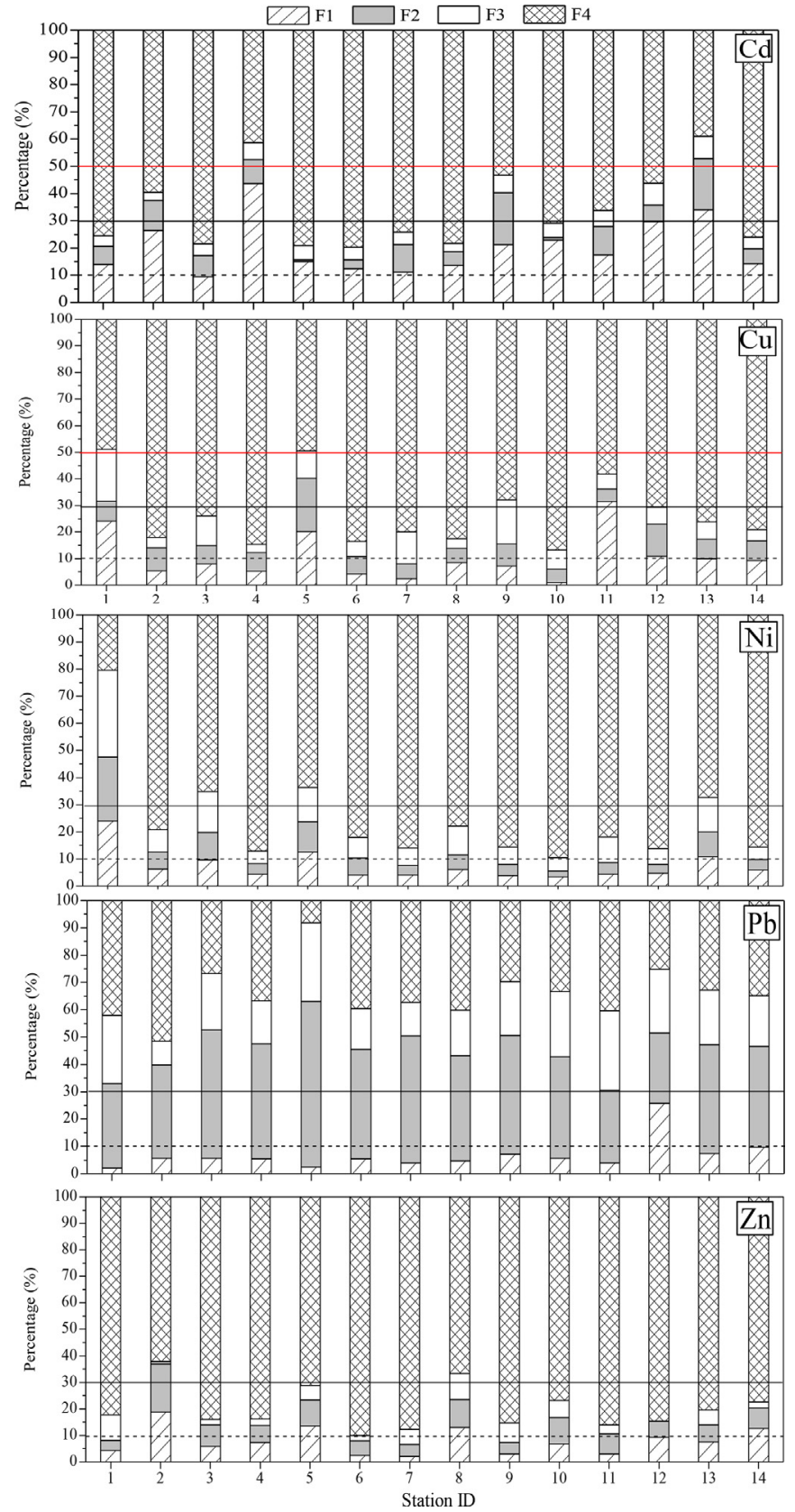

Fig. 4. The distributions of studied metals in different geochemical phases of the surface sediments from the Zaozhuang Segment. The horizontal dash lines represent RAC values (\%) of 10 . The horizontal solid lines represent RAC values (\%) of 30 or 50.

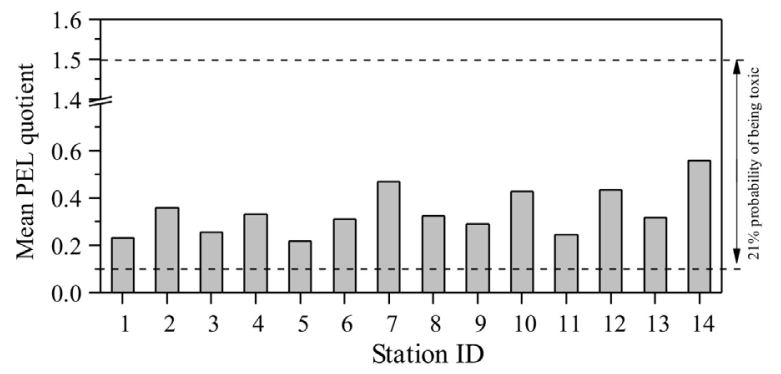

Fig. 5. The spatial distribution of mean PEL quotient values in the surface sediments of the Zaozhuang Segment. 
Table 2

The concentration of AVS and SEM in sediments of each sampling site.

\begin{tabular}{lrcccccc}
\hline Site & {$[$ AVS $]$} & {$[S E M]_{\mathrm{Cd}}$} & {$[\mathrm{SEM}]_{\mathrm{Cu}}$} & {$[\mathrm{SEM}]_{\mathrm{Ni}}$} & {$[\mathrm{SEM}]_{\mathrm{Pb}}$} & {$[\mathrm{SEM}]_{\mathrm{Zn}}$} & $\Sigma[\mathrm{SEM}]$ \\
\hline 1 & 1.83 & 0.0011 & 0.06 & 0.26 & 0.058 & 0.26 & 0.63 \\
2 & 1.92 & 0.0017 & 0.13 & 0.32 & 0.072 & 0.55 & 1.07 \\
3 & 1.62 & 0.0009 & 0.10 & 0.23 & 0.059 & 0.55 & 0.94 \\
4 & 1.28 & 0.0013 & 0.15 & 0.32 & 0.039 & 0.52 & 1.03 \\
5 & 0.91 & 0.0008 & 0.08 & 0.23 & 0.034 & 0.33 & 0.67 \\
6 & 3.60 & 0.0009 & 0.12 & 0.30 & 0.053 & 0.32 & 0.79 \\
7 & 1.08 & 0.0009 & 0.16 & 0.51 & 0.043 & 0.44 & 1.16 \\
8 & 2.88 & 0.0007 & 0.14 & 0.34 & 0.034 & 0.36 & 0.87 \\
9 & 1.49 & 0.0011 & 0.13 & 0.29 & 0.024 & 0.35 & 0.80 \\
10 & 1.47 & 0.0010 & 0.07 & 0.51 & 0.048 & 0.48 & 1.11 \\
11 & 1.22 & 0.0009 & 0.14 & 0.23 & 0.049 & 0.36 & 0.77 \\
12 & 1.21 & 0.0008 & 0.12 & 0.50 & 0.014 & 0.74 & 1.37 \\
13 & 1.61 & 0.0011 & 0.18 & 0.30 & 0.034 & 0.74 & 1.25 \\
14 & 1.19 & 0.0011 & 0.18 & 0.66 & 0.039 & 0.73 & 1.62 \\
Mean. & 1.67 & 0.0010 & 0.13 & 0.36 & 0.043 & 0.48 & 1.01 \\
RSD (\%) & 42.74 & 25.49 & 29.23 & 36.16 & 33.93 & 33.29 & 26.97 \\
\hline
\end{tabular}

Unit: $\mu \mathrm{mol} \mathrm{g}^{-1}$ (dry weight).

\subsubsection{Risk assessment code (RAC)}

Values corresponding to the RAC classification standard have been lined out in relevant positions illustrated in Fig. 4. In the research area, the RAC values of Cd were between $9.4 \%$ and $43.6 \%$ with an average value of $20.4 \%$ exhibiting a medium-level biological risk; however, high biological risks were shown in Location 4 and 13 . For $\mathrm{Cu}$, the RAC values was between $1.1 \%$ and $31.4 \%$ with an average value of $10.5 \%$ showing a medium-low-level biological risk; among them, Location 11 had a high biological risk. With regard to $\mathrm{Ni}$, its RAC ranged from $3.3 \%$ to $24.1 \%$ with an average value of $7.5 \%$ showing a biological risk of low level. Regarding $\mathrm{Pb}$, the RAC values were between $2.2 \%$ and 25.7 with an average value of $6.8 \%$ showing a low-level biological risk; medium-level risk existed only in Location 12 . Concerning $\mathrm{Zn}$, the RAC values were between $1.1 \%$ and $11.5 \%$ with an average value of $5.1 \%$ displaying a biological risk of low level except Location 2 and 12 in which the risk level for $\mathrm{Zn}$ just reached the medium level. Generally, RAC analysis indicated that the biological risks for such five heavy metals in this area were universally low.

\subsubsection{AVS-SEM guideline}

AVS and SEM concentrations in surface sediments of Zaozhuang Segment have been listed in Table 2. Within the entire segment, concentration of AVS varied in a small range with a relative standard deviation of $42.7 \%$, a maximum value of $3.60 \mu \mathrm{mol} / \mathrm{g}$ and a minimum value of $0.91 \mu \mathrm{mol} / \mathrm{g}$. The average AVS concentration was $1.67 \mu \mathrm{mol} / \mathrm{g}$. In 14 surface sediments under survey, only the AVS concentration in one location was less than $1 \mu \mathrm{mol} / \mathrm{g}$, those in 11 locations were between $1 \mu \mathrm{mol} / \mathrm{g}$ and $2 \mu \mathrm{mol} / \mathrm{g}$ and greater than $2 \mu \mathrm{mol} / \mathrm{g}$ in the other 2 locations.

In comparison with the fluctuation of AVS in surface sediments, that of $\Sigma$ SEM concentration was small ranging from $0.63 \mu \mathrm{mol} / \mathrm{g}$ to $1.62 \mu \mathrm{mol} / \mathrm{g}$ with a variable coefficient of $26.97 \%$ (Table 2 ). In each sampling site, $\mathrm{SEM}_{\mathrm{Zn}}$ and $\mathrm{SEM}_{\mathrm{Ni}}$ occupied the most of $\Sigma S E M$ and the contribution ratio of $S_{C M}$ to $\Sigma S E M$ was the smallest which further reflected the contributions of surrounding non-ferrous metal smelting emissions to the heavy metal in sediments.

The average difference between SEM and AVS in the research area was less than 0 (Fig. 6). For 14 sampling sites, the values of [SEM] - [AVS] in Location 7, 12 and 14 were greater than 0 indicating that the heavy metal in sediments of such locations might generate bio-toxicity. Furthermore, as difference values between SEM and AVS in those locations were all less than 5, the heavy metal in sediments produced bio-toxicity occasionally. Under normal conditions, the content of AVS in sediments varied with seasonal changes and it was lower in winter than in summer. Samples of

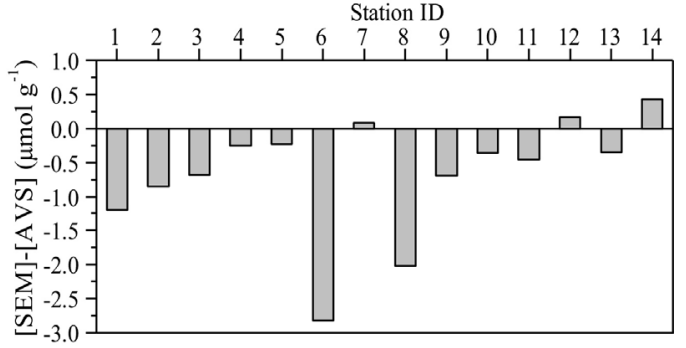

Fig. 6. Spatial distribution of $[S E M]-[A V S]$ in surface sediments of the Zaozhuang Segment.

this study were collected in spring so that the AVS concentrations were far from reaching their maximum values. With the rise of temperature, content of AVS also increased while the criticality of heavy metal in sediments might otherwise decrease. Without doubt, as AVS was in a state of dynamic change in sediments and its concentration was able to reduce because of re-suspension and bioturbation, bio-availability of the heavy metal in sediments could be hence improved.

\subsubsection{Multivariable evaluation index (MEI)}

MEI evaluation results in the research area were shown in Fig. 7. The zone with the highest MEI value was in Location 4 which was followed by Location 12 and 13. For MEI values around Location 3, 6,7 and 8 , they were relatively low, which was significantly different from analytical results based on TEL-PEL and AVS-SEM. For example, TEL-PEL and AVS-SEM showed that the risk of heavy metal in Location 7 was rather high. In addition, MEI values in locations nearby Taierzhuang District were relatively high, and this shared resemblance with TEL-PEL and AVS-SEM evaluation results.

From Fig. 8, it can be seen that the heavy metal assessment results between mean PEL quotient and AVS-SEM had prominent correlation $(r>0.4)$. However, when MEI was adopted to carry out risk assessment, it turned out that no significant correlation $(r<0.4)$ existed between evaluation results for MEI and mean PEL quotient as well as between MEI and AVS-SEM. Such discrepancies might be generated because of differences in physical absorptions of metal elements and sediments, chemical bond fastness and toxicity intensity. Comparing with the gross of heavy metal in sediments or fractionations which are only considered, MEI method is able to reveal contamination and ecological risk conditions of heavy metal in aquatic sediment environments more truly.

In most cases, the TEL-PEL assessment method only considers the gross of a heavy metal in sediments while neglects the mobility and bio-availability of its exchangeable form as well as the carbonate bounded form. As a result, potential heavy metal risks may be underestimated. Undoubtedly, the assessment method based on percentage compositions of the exchangeable and the carbonate bounded forms mainly indicates potential mobility of the heavy

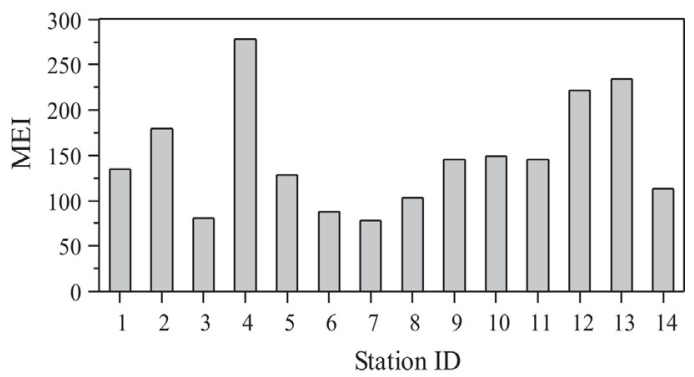

Fig. 7. The spatial distribution of multivariable evaluation index values in the surface sediments of the Zaozhuang Segment. 

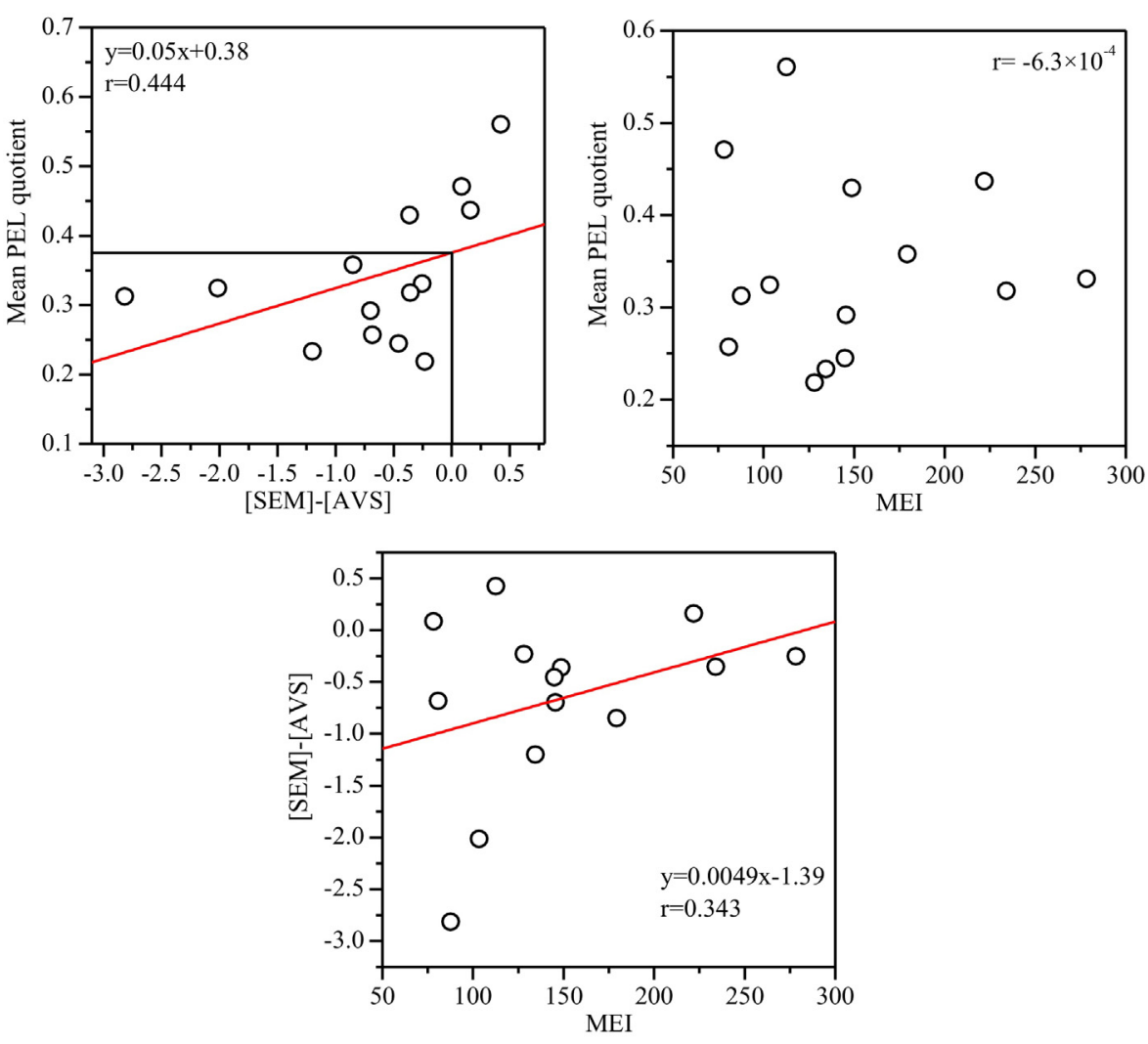

Fig. 8. Scatterplots (with linear regression line superimposed) among MEI, mean PEL quotient and [SEM]-[AVS] for 14 sites sampled in the Zaozhuang Section.

metal in sediments regardless of its actual gross. The adoption of such a method may give rise to misleading conclusions of heavy metal risk assessment. For instance, if the gross of heavy metal is so low that it is impossible for it to generate biological toxicity effects, because no toxic action can be created for organisms even though exchangeable and carbonate bounded forms occupy a high proportion. Additionally, as different heavy metals have different bio-toxicity intensities, toxicity response coefficient is introduced to reflect the capability of various heavy metals to generate biotoxicity in a more realistic manner.

Thus, it may be concluded that MEI could discover other aspects of metal pollution and ecological risk in sediments of a particular area. Overall, the application of MEI may provide deeper insight in the assessment of metal pollution risk of sediments. MEI seems to be able to overcome the limitations of other prevalent aggregated indexes to assess potential sediment pollution risk in aquatic systems.

\section{Conclusion}

In this paper, contents, chemical forms and potential risks were studied for $\mathrm{Cd}, \mathrm{Cu}, \mathrm{Ni}, \mathrm{Pb}$ and $\mathrm{Zn}$ in surface sediments in Zaozhuang Segment of the Beijing-Hangzhou Grand Canal. Results showed that their contents were generally rather low in Zaozhuang Segment. Fractionation analysis also indicated that $\mathrm{Cd}, \mathrm{Cu}, \mathrm{Ni}$ and $\mathrm{Zn}$ existed mainly in residual form with an overall low bio-availability. Cd had a relatively higher percentage composition of exchangeable and carbonate bounded forms, showing a powerful bio-availability that the other metals. As far as Pb was concerned, its contents of reducibility and oxidability forms were very high signifying that it had potential bio-availability.

Obvious discrepancies existed in evaluation results acquired based on different assessment methods. The analytical results on the basis of TEL-PEL showed that unlike the other four heavy metals with low perniciousness, $\mathrm{Ni}$ was potentially dangerous to organisms in the studied area. According to the analysis result of mean PEL quotient calculation, it could be known that the comprehensive toxicity occurrence probability of the five heavy metals was $21 \%$ for all the locations. RAC analysis made it clear that except in several locations, ecological risk of the five heavy metals were all low in the studied area. The analysis on account of AVS-SEM also indicated that only the heavy metal in sediments of 3 locations was able to produce bio-toxicity.

In case that MEI was adopted to carry out risk assessment, because toxicity intensity of metal, percentage compositions of exchangeable form and carbonate bounded form as well as AVS content had been taken into account in the meantime, MEI was greatly different from results obtained through other evaluation methods. In addition, it might be concluded that MEI could discover other aspects of metal pollution and ecological risk in sediments of a particular area. Without doubt, such a method has certain limitations. Due to the lack of a good deal of toxicological experiment, benthic community experiment, biological accumulation experiment and comprehensive experimental data, interval division approaches to risk grade still cannot be determined. However, with the launching of related experiments, methods of this kind will be improved day by day.

\section{Acknowledgements}

This study was co-supported by the Natural Science Foundation of Shandong Province, China (ZR2014DP005) and the Research Fund for the Doctoral Program of Zaozhuang University, China (2014BS11, 2014BS14). We appreciate Editor João Carlos Marques and anonymous referees, whose constructive comments allowed us to improve the manuscript. 


\section{References}

Allen, H.E., Fu, G., Deng, B., 1993. Analysis of acid-volatile sulfide (AVS) and simultaneously extracted metals (SEM) for the estimation of potential toxicity in aquatic sediments. Environ. Toxicol. Chem. 12, 1441-1453.

Bagarinao, T., 1992. Sulfide as an environmental factor and toxicant: tolerance and adaptations in aquatic organisms. Aquat. Toxicol. $24(1-2)$, 21-62

Bastami, K.D., Bagheri, H., Haghparast, S., Soltani, F., Hamzehpoor, A., Bastami, M.D., 2012. Geochemical and geo-statistical assessment of selected heavy metals in the surface sediments of the Gorgan Bay, Iran. Mar. Pollut. Bull. 64 (12), 2877-2884.

Brouwer, H., Murphy, T.P., 1994. Diffusion method for the determination of acid-volatile sulphides (AVS) in sediment. Environ. Toxicol. Chem. 13 $1273-1275$

Carlson, A.R., 1991. The role of acid-volatile sulfide in determining cadmium bioavailability and toxicity in freshwater sediments. Environ. Toxicol. Chem. 10, 1309-1316.

De Jonge, M., Dreesen, F., De Paepe, J., Blust, R., Bervoets, L., 2009. Do acid volatile sulfides (AVS) influence the accumulation of sediment-bound metals to benthic invertebrates under natural field conditions? Environ. Sci. Technol. 43, 4510-4516

De Jonge, M., Blust, R., Bervoets, L., 2010. The relation between acid volatile sulfides (AVS) and metal accumulation in aquatic invertebrates: implications of feeding behavior and ecology. Environ. Pollut. 158, 1381-1391.

De Jonge, M., Teuchies, J., Meire, P., Blust, R., Bervoets, L., 2012. The impact of increased oxygen conditions on metal-contaminated sediments part I: effects on redox status, sediment geochemistry and metal bioavailability. Water Res. 46, 2205-2214.

Di Toro, D.M., Mahony, J.D., Hansen, D.J., Scott, K.J., Hicks, M.B., Mayr, S.M., Redmond, M.S., 1990. Toxicity of cadmium in sediments: the role of acid volatile sulfide. Environ. Toxicol. Chem. 9 (12), 1487-1502.

Di Toro, D.M., McGrath, J.A., Hansen, D.J., Berry, W.J., Paquin, P.R., Mathew, R., Wu, K.U., Santore, R.C., 2005. Predicting sediment metal toxicity using a sediment biotic ligand model: methodology and initial application. Environ. Toxicol. Chem. 24 (10), 2410-2427.

Fytianos, K., Lourantou, A., 2004. Speciation of elements in sediment samples collected at lakes Volvi and Koronia, N. Greece. Environ. Int. 30, $11-17$

Gao, X.L., Chen, C.T.A., Wang, G., Xue, Q.Z., Tang, C., Chen, S.Y., 2010. Environmental status of Daya Bay surface sediments inferred from a sequential extraction technique. Estuar. Coast. Shelf Sci. 86, 369-378.

Gao, X.L., Zhou, F.X., Chen, C.T.A., 2014. Pollution status of the Bohai Sea, China: an overview of the environmental quality assessment related trace metals. Environ. Int. 62, 12-30.

Gibbs, R.J., 1977. Transport Phases of transition metals in the Amazon and Yukon Rivers. Geol. Soc. Am. Bull. 88, 829-843.

Hakanson, L., 1980. An ecological risk index for aquatic pollution control. A sedimentological approach. Water Res. 14, 975-1001.

Hinkey, L.M., Zaidi, B.R., 2007. Differences in SEM-AVS and ERM-ERL predictions of sediment impacts from metals in two US Virgin Islands marinas. Mar. Pollut. Bull. 54, 180-185

Leonard, E.N., Cotter, A.M., Ankley, G.T., 1996. Modified diffusion method for analysis of acid volatile sulphides and simultaneously extracted metals in freshwater sediment. Environ. Toxicol. Chem. 15, 1479-1481.
Long, E.R., MacDonald, D.D., Severn, C.G., Hong, C.B., 2000. Classifying probabilities of acute toxicity in marine sediments with empirically derived sediment quality guideline. Environ. Toxicol. Chem. 19, 2598-2601.

MacDonald, D.D., Scottcarr, R., Calder, F.D., Long, E.R., Ingersoll, C.G., 1996. Development and evaluation of sediment quality guidelines for Florida coastal waters. Ecotoxicology 5, 253-278.

McGrath, J.A., Paquin, P.R., Di Toro, D.M., 2002. Use of the SEM and AVS Approach in Predicting Metal Toxicity in Sediments. Fact Sheet on Environmental Risk Assessment. International Council on Mining and Metals (ICMM), London, UK (No. 10).

Moore, T.R., Souza, W.A., Koprivanjak, J.F., 1992. Controls on the sorption of dissolved organic carbon by soul. Soil Sci. 2, 120-129.

Morse, J.W., Millero, F.J., Cornwell, J.C., Rickard, D., 1987. The chemistry of hydrogen sulfide and iron sulfide systems in natural waters. Earth Sci. Rev. 24, 1-42.

Perin, G., Craboledda, L., Lucchese, L., Cirillo, R., Dotta, L., Orio, A.A., 1985. Heavy metal speciation in the sediments of Northern Adriatic Sea: a new approach for environmental toxicity determination. In: Lekkas, T.D. (Ed.), Heavy Metal in the Environment, vol. 2. CEP Consultant, Edinburgh, pp. 454-456.

Rauret, G., López-Sánche, J.F., Sahuquillo, A., Rubio, R., Davidson, C., Ure, A. Quevauviller, P., 1999. Improvement of the BCR three step sequential extraction procedure prior to the certification of new sediment and soil reference materials. J. Environ. Monit. 1, 57-61.

Saeedi, M., Jamshidi-Zanjani, A., 2015. Development of a new aggregative index to assess potential effect ofmetals pollution in aquatic sediments. Ecol. Indic. 58, 235-243.

Shen, J., Zhang, Z.L., Yang, L.Y., Sun, Q.Y., 2008. Nansihu Lake: Environmental and Resource Studies. Seismological Press, Beijing (in Chinese).

Sundaray, S.K., Nayak, B.B., Lin, S., Bhatta, D., 2011. Geochemical speciation and risk assessment of heavy metals in the river estuarine sediments-a case study Mahanadi basin, India. J. Hazard. Mater. 186, 1837-1846.

USEPA (United States Environmental Protection Agency), 2004. The Incidence and Severity of Sediment Contamination in Surface Waters of The United States (National Sediment Quality Survey. EPA-823-R-04-007, second edition. United States Environmental Protection Agency, Office of Science and Technology, Washington, DC.

van Griethuysen, C., Gillissen, F., Koelmans, A.A., 2002. Measuring acid volatile sulphide in floodplain lake sediments: effect of reaction time, sample size and aeration. Chemosphere 47, 395-400.

Zhang, R., Zhou, L., Zhang, F., Ding, Y.J., Gao, J.R., Chen, J., Yan, H.Q., Shao, W., 2013. Heavy metal pollution and assessment in the tidal flat sediments of Haizhou Bay. China. Mar. Pollut. Bull. 74, 403-412.

Zhao, Y.Y., Yan, M.C., 1992. Comparison of chemical element abundances in sediments of the Yellow River, the Changjiang River and the shallow seas of China. Chin. Sci. Bull. 13, 1202-1204 (In Chinese).

Zhuang, W., Gao, X.L., 2013. Acid-volatile sulfide and simultaneously extracted metals in surface sediments of the southwestern coastal Laizhou Bay, Bohai Sea Concentrations, spatial distributions and the indication of heavy metal pollution status. Mar. Pollut. Bull. 76, 128-138.

Zhuang, W., Gao, X.L., 2014. Integrated assessment of heavy metal pollution in the surface sediments of the Laizhou Bay and the coastal waters of the Zhangz Island, China: comparison among typical marine sediment quality indices. PLoS One 9, e94145.

Zhuang, W., Gao, X.L., 2015. Distribution, enrichment and sources of thallium in the surface sediments of the southwestern coastal Laizhou Bay, Bohai Sea. Mar. Pollut. Bull. 96, 502-507. 